\title{
Genus Lepocinclis (Euglenophyceae) along five years in the area of influence of the Southern Petrochemical Pole, Rio Grande do Sul State, Brazil
}

\author{
Sandra Maria Alves-da-Silva ${ }^{1,3}$, Carlos Eduardo de Mattos Bicudo ${ }^{2}$, Karina Federle Consoni ${ }^{1}$, \\ Lusiane Soares da Silva ${ }^{1}$ and Camila de Leon Lousada Borges ${ }^{1}$
}

Received: 1.10.2010; accepted: 9.06.2011

\begin{abstract}
Genus Lepocinclis (Euglenophyceae) along five years in the area of influence of the Southern Petrochemical Pole, Rio Grande do Sul State, Brazil). As part of an Euglenophyte's survey carried out during 2002-2006 at three different sites of Bom Jardim Creek, 13 Lepocinclis taxa were identified at species and infraspecific level. Bom Jardim Creek is a right side affluent of Caí River, Municipality of Triunfo, State of Rio Grande do Sul, and has its almost entire $10.5 \mathrm{~km}$ length within the Southern Petrochemical Pole area. Local climate is subtropical. Samplings were carried out monthly both for biological and abiotic analyses. Among the taxa identified, Lepocinclis fusiformis (Carter) Lemmermann emend. Conrad, L. ovum (Ehrenberg) Lemmermann var. dimidio-minor Deflandre and Lepocinclis salina Fritsch var. salina were the broadest geographically distributed ones in the creek during all five years, due to their standing to a wide range of environmental conditions. Seasonal species richness variation was observed in all creek sampling sites, summer being significantly different from all other climatic seasons of the year.
\end{abstract}

Key words: Euglenophyta, Lepocinclis, Southern Brazil, taxonomy

RESUMO - (O gênero Lepocinclis (Euglenophyceae) ao longo de cinco anos na área de influência do Pólo Petroquímico do Sul, Estado do Rio Grande do Sul, Brasil). Como parte do resultado do levantamento da comunidade de Euglenophyta realizado entre 2002 e 2006 em três trechos do arroio Bom Jardim foram identificados 13 Lepocinclis em níveis específico e infraespecífico. O arroio Bom Jardim é um afluente da margem direita do rio Caí, Município de Triunfo, no Rio Grande do Sul com quase todo seu percurso de 10,5 km situado na área do Pólo Petroquímico do Sul. O clima local é subtropical. As coletas foram realizadas mensalmente tanto para as análises biológicas quanto para as abióticas. Dentre os táxons identificados, Lepocinclis fusiformis (Carter) Lemmermann emend. Conrad, L. ovum (Ehrenberg) Lemmermann var. dimidio-minor Deflandre and $L$. salina Fritsch var. salina foram os que apresentaram a maior distribuição no arroio e suportaram ampla variação das condições ambientais. Foi constatada variação sazonal quanto à riqueza de espécies entre os três trechos do arroio, sendo o verão significativamente diferente das demais estações do ano.

Palavras-chave: Euglenophyta, Lepocinclis, Sul do Brasil, taxonomia

\section{Introduction}

Euglenophytes are present all over the world, especially in shallow, nutrient rich environments (Round 1983, Wetzel 2001). The State of Rio Grande do Sul includes a number of lentic and lotic environments that favor the existence of representatives of this algal group.
First papers published on the Euglenophytes flora from Rio Grande do Sul State freshwater systems are simple lists of genera and species, such as the ones by Rosa et al. (1974), Torgan et al. (1979), Lobo \& Buselato-Toniolli (1985), Rosa et al. (1987) and Rosa et al. (1988). During the last three decades, however, Euglenophytes floristic surveys included descriptions and illustrations of material studied. Sommer (1977,

1. Fundação Zoobotânica do Rio Grande do Sul, Museu de Ciências Naturais, Cryptogamic Botany Section, Caixa Postal 1188, 90001-970 Porto Alegre, Rio Grande do Sul, Brasil

2. Instituto de Botânica, Ecology Department, Caixa Postal 68041, 04045-972 São Paulo, SP, Brasil

3. Author for correspondence: alvesdasilva@fzb.rs.gov.br 
not published), Huszar (1979), Alves-da-Silva \& Torgan (1981), Alves-da-Silva (1988), Alves-da-Silva \& Ferraz (1991), Alves-da-Silva et al. (1991, 2008), Franceschini (1992), Alves-da-Silva \& Torres (1992, 1994a, b, c), Alves-da-Silva \& Laitano (1994), Alvesda-Silva \& Ávila (1997), Alves-da-Silva \& Bicudo (2002, 2003, 2006), Alves-da-Silva \& Crosssetti (1999), Alves-da-Silva \& Hahn (2004) and Alves-daSilva \& Fortuna (2006) are examples of such publications.

Despite of the worldwide distribution of Lepocinclis in freshwaters, taxonomic revision papers are almost 80 years old and are reduced to those of Conrad $(1934,1935)$ and Chu $(1935,1936)$. Most of present knowledge of Lepocinclis is in Euglenophytes general floristic papers, such as the ones by Lemmernann (1910), Drezepolski (1925), HuberPestalozzi (1955), Starmach (1983) and Tell \& Conforti (1986).

Several papers were published during the last two decades based on molecular biology attempting to elucidate taxonomic and phylogenetic problems within the Euglenophyceae, among them the works of Linton et al. (1999, 2000), Preisfeld et al. (2000, 2001), Leander et al. (2001), Busse \& Preisfeld (2002, 2003), Brosnan et al. (2003), Marin et al. (2003) and Kosmala et al. 2005 can be highlighted. Emphasis should be given, however, to that by Marin et al. (2003) that compared Euglena, Astasia, Phacus, Lepocinclis, Trachelomonas, Colacium, Cryptoglena, Eutreptia, Eutreptiella and Tetreutreptia lineages. Last authors proposed that some species of the Rigidae Pringsheim Section of Euglena (for instance, E. acus, E. oxyuris and E. spirogyra), should be transferred to Lepocinclis. Besides the papers dealing with molecular biology, some other ones focused on the morphological aspects were carried out, especially on the structure and origin of the pellicle striae (Brosnan et al. 2005, Esson \& Leander 2006, Leander \& Farmer 2000a, b, Leander \& Farmer 2001a, b, Leander et al. 2001, among others). Latter investigations showed that there are significant differences in the number, origin and type of striae among genera and species of Euglenophytes. There is, however, and enormous lack of studies dealing with Lepocinclis species (most with helicoidal striae) and absolutely none that would include, for example, Euglena acus, that has longitudinal striae.

Marin et al. (2003) proposal based on SSU rDNA sequence comparisons and synapomorphic signatures in the SSU rDNA secondary structure encompassed species that are very much different among themselves if cell morphology and metaboly, pellicle structure and paramylum granules morphology are considered.

Present research aimed at broadening knowledge and geographical distribution of genus Lepocinclis in the State of Rio Grande do Sul and worldwide, as well as knowing the interaction of different taxa with environmental conditions during the period 2002-2006. It is important to mention that the present is the first Lepocinclis long duration study ever carried out in Brazil.

\section{Material and methods}

Survey of genus Lepocinclis of Bom Jardim Creek, a right margin affluent of Caí River, in the Municipality of Triunfo, Rio Grande do Sul State was carried out during the period 2002-2006. The creek has almost its entire $10.5 \mathrm{~km}$ course within the Southern Petrochemical Pole area, and has an average declivity of $3.2 \mathrm{~m}$, with portions with more intense current intercalated with some others of very calm waters. Altitude at its meeting point with the Caí River is less than $5 \mathrm{~m}$.

Study derived from net samples collected between 2002 and 2006 at 3 Bom Jardim Creek sites (figure 1), namely ABJ Nascente located at 29.49'36"S and $51^{\circ} 27^{\prime} 11^{\prime \prime} \mathrm{W}, \mathrm{ABJ}$ Montante $\left(29^{\circ} 50^{\prime} 21^{\prime \prime} \mathrm{S}\right.$ and $\left.51^{\circ} 24^{\prime} 58^{\prime \prime} \mathrm{W}\right)$ and ABJ Frente (29 $50^{\circ} 12^{\prime \prime} \mathrm{S}$ and $51^{\circ} 23$ '25' W), where SITEL are the initial letters for Sistema de Tratamento de Efluentes Líquidos (Treatment System of Liquid Effluents) of the Southern Petrochemical Pole. Station ABJ Nascente is located in the creek shallowest part ( $\leq 30 \mathrm{~cm}$ deep), close to the place were cows and sheep live, station ABJ Montante in the creek portion $(\leq 80 \mathrm{~cm}$ deep) that receives human source contamination from a village with no sewage collection, and station $\mathrm{ABJ}$ Frente $(\leq 130 \mathrm{~cm}$ deep) in the creek portion under the Petrochemical Pole influence.

Local climate is subtropical, with well marked seasons, summer including January-March, Fall AprilJune, winter July-September and Spring OctoberDecember. Rain precipitation yearly average for the state is $1,500 \mathrm{~mm}$, the greatest monthly total precipitation in June-July (Conti \& Furlan 2003).

Samples were gathered monthly from the creek's margin with a plankton net built with a $25 \mu \mathrm{m}$ mesh 


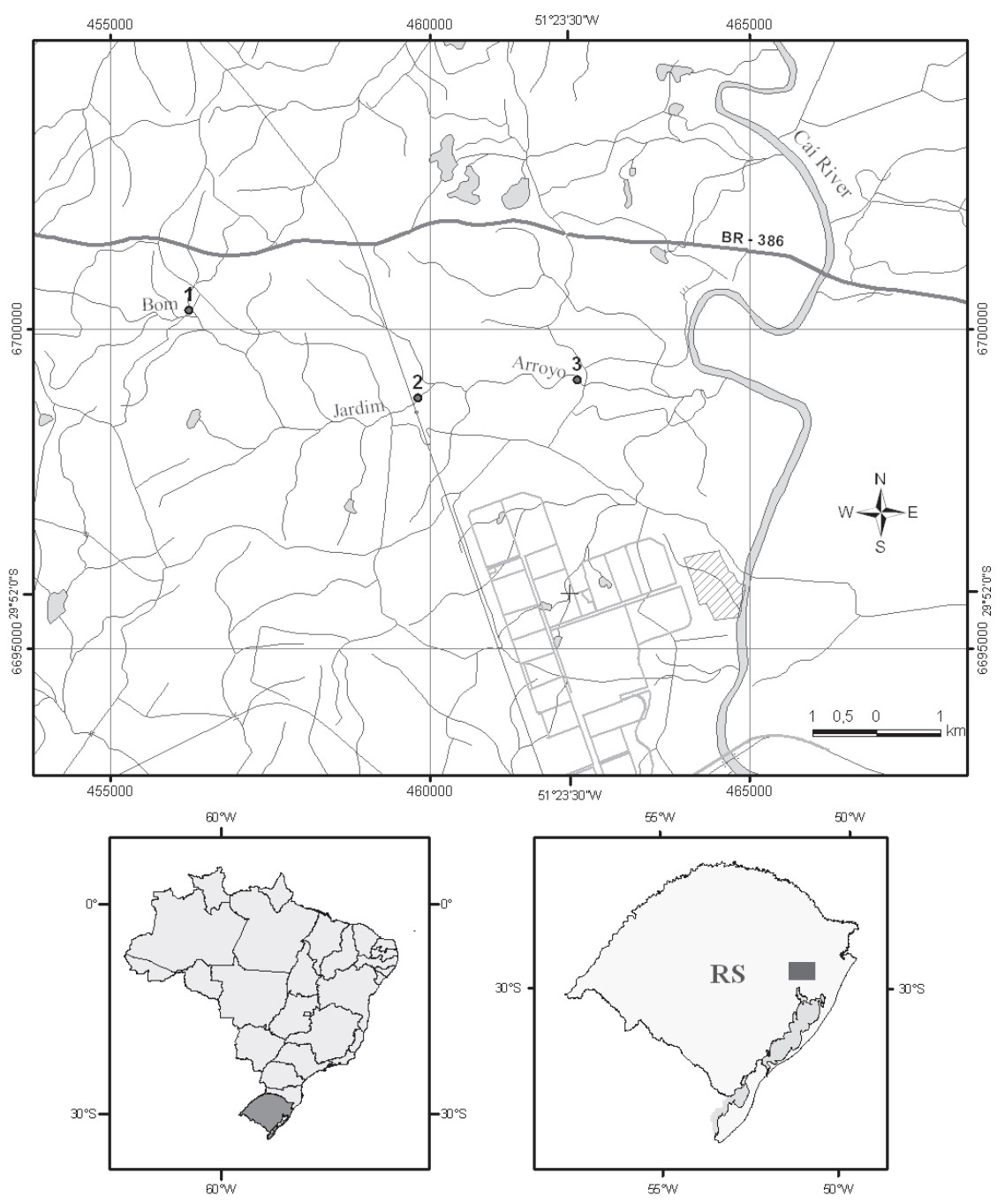

Figure 1. Location of the 3 sampling sites in the Bom Jardim Creek, Municipality of Triunfo, Rio Grande do Sul State, Brazil, during period from 2002 to 2006 .

tissue, and were fixed and preserved with $4 \%$ formaldehyde. Due to technical problems, samples were not collected in May 2002 at the 3 sites and from ABJ Nascente in January 2006.

All 176 samples collected are deposited in the Herbarium Prof. Dr. Alarich R.H. Schultz (HAS) of the Natural Sciences Museum (Museu de Ciências Naturais), of the Zoological and Botanical Foundation (Fundação Zoobotânica of the State of Rio Grande do Sul) (table 1).

Analyses of algal material were performed using regular microscope slide and cover slip and a Leica microscope with measuring ocular. Illustrations were prepared using a camera lucida coupled to the microscope optical system.

Simultaneously to phytoplankton samplings, measurements in the field were taken for water transparency with a $0.25 \mathrm{~m}$ diam. Secchi disc, $\mathrm{pH}$ with a Digimed pHmeter, water electric conductivity and temperature with a Digimed conductivimeter. In the laboratory, concentrations of dissolved oxygen, oxygen biochemical demand, $\mathrm{N}_{-} \mathrm{NH}_{4}{ }^{+}, \mathrm{N}-\mathrm{NO}_{2}{ }^{-}$, $\mathrm{N}-\mathrm{NO}_{3}{ }^{-}, \mathrm{P}_{-} \mathrm{PO}_{4}^{-3}$, silicates and organic matter were measured following proper methods in APHA (1992) (table 2).

Besides linear measurements of cell length and breadth, the rate between cell length and breadth (R 1/b) was calculated. Illustration, geographic distribution in Brazil and information about the environment variables range under which each taxon was collected is also provided.

For species and infraspecific categories identification, ancient and recent classical works (Conrad 1935, Huber-Pestalozzi 1955, Németh 1980, 
Table 1. Sample's access numbers to Prof. Dr. R. H. Schultz (HAS) herbarium, collecting locality, date, climatic season, and collector's names of Lepocinclis material in the 3 Bom Jardim Creek portions during 2002-2006. Legend: ABJNascente = spring; ABJMS = upper stream from Sitel; ABJFS = in front of Sitel, $\mathrm{V}=$ summer; $\mathrm{O}=$ fall, $\mathrm{I}=$ winter, $\mathrm{P}=$ spring e $\mathrm{NR}=$ collection not performed.

\begin{tabular}{|c|c|c|c|c|c|c|c|c|c|}
\hline $\mathrm{N}^{\circ} \mathrm{HAS}$ & $\begin{array}{l}\text { Sampling } \\
\text { station }\end{array}$ & Date & $\begin{array}{l}\text { Season } \\
\text { of year }\end{array}$ & Collector & $\mathrm{N}^{\circ} \mathrm{HAS}$ & $\begin{array}{l}\text { Sampling } \\
\text { station }\end{array}$ & Date & $\begin{array}{l}\text { Season } \\
\text { of year }\end{array}$ & Collector \\
\hline 103163 & ABJNasc & $14-\mathrm{I}-2002$ & $\mathrm{~V}$ & Silva, S.M.A. & 103993 & ABJNasc & 7-IV-2003 & $\mathrm{O}$ & Silva,S.M.A. \\
\hline 35999 & ABJMS & $14-I-2002$ & $\mathrm{~V}$ & Silva, S.M.A. & 103996 & ABJMS & 7-IV-2003 & $\mathrm{O}$ & Silva,S.M.A. \\
\hline 103156 & ABJFS & $14-I-2002$ & $\mathrm{~V}$ & Silva, S.M.A. & 103999 & ABJFS & 7-IV-2003 & $\mathrm{O}$ & Silva,S.M.A. \\
\hline 103202 & ABJNasc & 6-II-2002 & V & Nunes, M. & 104014 & ABJNasc & $5-V-2003$ & $\mathrm{O}$ & Cunha, G. \\
\hline 103188 & ABJMS & 6-II-2002 & $\mathrm{V}$ & Nunes, M. & 104017 & ABJMS & $5-\mathrm{V}-2003$ & $\mathrm{O}$ & Cunha, G. \\
\hline 103195 & ABJFS & 6-II-2002 & $\mathrm{V}$ & Nunes, M. & 104020 & ABJFS & $5-V-2003$ & $\mathrm{O}$ & Cunha, G. \\
\hline 103249 & ABJNasc & 25-III-2002 & V & Silva, S.M.A. & 104039 & ABJNasc & 2-VI-2003 & $\mathrm{O}$ & Silva, S.M.A. \\
\hline 103250 & ABJMS & 25-III-2002 & V & Silva, S.M.A. & 104042 & ABJMS & 2-VI-2003 & $\mathrm{O}$ & Silva, S.M.A. \\
\hline 103254 & ABJFS & 25-III-2002 & $\mathrm{V}$ & Silva, S.M.A. & 104045 & ABJFS & 2-VI-2003 & $\mathrm{O}$ & Silva, S.M.A. \\
\hline 103391 & ABJNasc & 22-IV-2002 & $\mathrm{O}$ & Silva, S.M.A. & 104064 & ABJNasc & 1-VII-2003 & I & Silva, S.M.A. \\
\hline 103394 & ABJMS & 22-IV-2002 & $\mathrm{O}$ & Silva, S.M.A. & 104067 & ABJMS & 1-VII-2003 & I & Silva, S.M.A. \\
\hline 103397 & ABJFS & 22-IV-2002 & $\mathrm{O}$ & Silva, S.M.A. & 104070 & ABJFS & 1-VII-2003 & I & Silva, S.M.A. \\
\hline NR & ABJNasc & NR & $\mathrm{O}$ & NR & 104277 & ABJNasc & 4-VIII-2003 & I & Silva, S.M.A. \\
\hline NR & ABJMS & NR & $\mathrm{O}$ & NR & 104280 & ABJMS & 4-VIII-2003 & I & Silva, S.M.A. \\
\hline NR & ABJFS & NR & $\mathrm{O}$ & NR & 104283 & ABJFS & 4-VIII-2003 & I & Silva, S.M.A. \\
\hline 103420 & ABJNasc & $6-\mathrm{VI}-2002$ & $\mathrm{O}$ & Silva, S.M.A. & 104298 & ABJNasc & 1-IX-2003 & I & Salomoni, S \\
\hline 103423 & ABJMS & 6-VI-2002 & $\mathrm{O}$ & Silva, S.M.A. & 104301 & ABJMS & 1-IX-2003 & I & Salomoni, S \\
\hline 103426 & ABJFS & $6-\mathrm{VI}-2002$ & $\mathrm{O}$ & Silva, S.M.A. & 1043 & ABJFS & 1-IX-2003 & I & Salomoni, S \\
\hline 103457 & ABJNasc & 3-VII-2002 & I & Silva, S.M.A. & 104316 & ABJNasc & $1-X-2003$ & $\mathrm{P}$ & Silva, S.M.A. \\
\hline 103459 & ABJMS & 3-VII-2002 & I & Silva, S.M.A. & 104319 & ABJMS & $1-X-2003$ & $\mathrm{P}$ & Silva, S.M.A. \\
\hline 103458 & ABJFS & 3-VII-2002 & I & Silva, S.M.A. & 104322 & ABJFS & $1-X-2003$ & $\mathrm{P}$ & Silva, S.M.A. \\
\hline 103521 & ABJNasc & 5-VIII-2002 & I & Cunha, G. & 104522 & ABJNasc & $3-X I-2005$ & $\mathrm{P}$ & Silva, S.M.A. \\
\hline 103524 & ABJMS & 5-VIII-2002 & I & Cunha, G. & 104525 & ABJMS & $3-X I-2005$ & $\mathrm{P}$ & Silva, S.M.A. \\
\hline 103527 & ABJFS & 5-VIII-2002 & I & Cunha, G. & 104528 & ABJFS & $3-X I-2005$ & $\mathrm{P}$ & Silva, S.M.A. \\
\hline 103615 & ABJNasc & 2-IX-2002 & I & Silva, S.M.A. & 104543 & ABJNasc & 1-XII-2003 & $\mathrm{P}$ & Werner, V. \\
\hline 103618 & ABJMS & 2-IX-2002 & I & Silva, S.M.A. & 104546 & ABJMS & 1-XII-2003 & $\mathrm{P}$ & Werner, V. \\
\hline 103621 & ABJFS & 2-IX-2002 & I & Silva, S.M.A. & 104549 & ABJFS & 1-XII-2003 & $\mathrm{P}$ & Werner, V. \\
\hline 103640 & ABJNasc & $7-X-2002$ & $\mathrm{P}$ & Cunha, G. & 104561 & ABJNasc & 5-I-2004 & V & Silva, S.M. da \\
\hline 103643 & ABJMS & $7-X-2002$ & $\mathrm{P}$ & Cunha, G. & 104564 & ABJMS & $5-I-2004$ & V & Silva, S.M. da \\
\hline 103646 & ABJFS & $7-X-2002$ & $\mathrm{P}$ & Cunha, G. & 104567 & ABJFS & $5-I-2004$ & V & Silva, S.M. da \\
\hline 103665 & ABJNasc & 14-XI-2002 & $\mathrm{P}$ & Silva, S.M.A. & 104582 & ABJNasc & $3-I I-2004$ & $\mathrm{~V}$ & Silva, S.M.A. \\
\hline 103668 & ABJMS & 14-XI-2002 & $\mathrm{P}$ & Silva, S.M.A. & 104585 & ABJMS & 3-II-2004 & V & Silva, S.M.A. \\
\hline 103671 & ABJFS & 14-XI-2002 & $\mathrm{P}$ & Silva, S.M.A. & 104588 & ABJFS & $3-I I-2004$ & V & Silva, S.M.A. \\
\hline 103690 & ABJNasc & 2-XII-2002 & $\mathrm{P}$ & Silva, S.M.A. & 104767 & ABJNasc & 16-III-2004 & V & Juliano, V. \\
\hline 103693 & ABJMS & 2-XII-2002 & $\mathrm{P}$ & Silva, S.M.A. & 104770 & ABJMS & 16-III-2004 & $\mathrm{V}$ & Juliano, V. \\
\hline 103696 & ABJFS & 2-XII-2002 & $\mathrm{P}$ & Silva, S.M.A. & 104773 & ABJFS & 16-III-2004 & $\mathrm{V}$ & Juliano, V. \\
\hline 103830 & ABJNasc & $6-\mathrm{I}-2003$ & V & Cunha, G. & 104783 & ABJNasc & 12-IV-2004 & $\mathrm{O}$ & Cunha, G. \\
\hline 103833 & ABJMS & 6-I-2003 & $\mathrm{V}$ & Cunha, G. & 104786 & ABJMS & 12-IV-2004 & $\mathrm{O}$ & Cunha, G. \\
\hline 103836 & ABJFS & $6-\mathrm{I}-2003$ & $\mathrm{~V}$ & Cunha, G. & 104789 & ABJFS & 12-IV-2004 & $\mathrm{O}$ & Cunha, G. \\
\hline 103856 & ABJNasc & $4-\mathrm{II}-2003$ & $\mathrm{~V}$ & Cunha, G. & 104804 & ABJNasc & $11-V-2004$ & $\mathrm{O}$ & Silva, S.M.A. \\
\hline 103859 & ABJMS & 4-II-2003 & V & Cunha, G. & 104807 & ABJMS & $11-V-2004$ & $\mathrm{O}$ & Silva, S.M.A. \\
\hline 103862 & ABJFS & $4-I I-2003$ & $\mathrm{~V}$ & Cunha, G. & 104810 & ABJFS & $11-V-2004$ & $\mathrm{O}$ & Silva, S.M.A. \\
\hline 103946 & ABJNasc & 10-III-2003 & $\mathrm{V}$ & Silva, S.M.A. & 104821 & ABJNasc & 7-VI-2004 & $\mathrm{O}$ & Silva, S.M.A. \\
\hline 103949 & ABJMS & 10-III-2003 & $\mathrm{V}$ & Silva, S.M.A. & 104824 & ABJMS & 7-VI-2004 & $\mathrm{O}$ & Silva, S.M.A. \\
\hline 103952 & ABJFS & 10-III-2003 & V & Silva, S.M.A. & 104827 & ABJFS & 7-VI-2004 & $\mathrm{O}$ & Silva, S.M.A. \\
\hline 104844 & ABJNasc & 13-VII-2004 & V & Cunha, G. & 106703 & ABJNasc & $10-X-2005$ & $\mathrm{P}$ & Silva, S.M.A. \\
\hline 104847 & ABJMS & 13-VII-2004 & $\mathrm{V}$ & Cunha, G. & 106706 & ABJMS & $10-X-2005$ & $\mathrm{P}$ & Silva, S.M.A. \\
\hline 104850 & ABJFS & 13-VII-2004 & $\mathrm{V}$ & Cunha, G. & 106709 & ABJFS & $10-X-2005$ & $\mathrm{P}$ & Silva, S.M.A. \\
\hline 106095 & ABJNasc & 9-VIII-2004 & $\mathrm{V}$ & Cunha, G. & 106716 & ABJNasc & 8-XI-2005 & $\mathrm{P}$ & Silva, S.M.A. \\
\hline 106098 & ABJMS & 9-VIII-2004 & $\mathrm{V}$ & Cunha, G. & 106718 & ABJMS & 8-XI-2005 & $\mathrm{P}$ & Silva, S.M.A. \\
\hline 106101 & ABJFS & 9-VIII-2004 & $\mathrm{V}$ & Cunha, G. & 106721 & ABJFS & 8-XI-2005 & $\mathrm{P}$ & Silva, S.M.A. \\
\hline 106116 & ABJNasc & 13-IX-2004 & $\mathrm{V}$ & Silva, S.M.A. & 106734 & ABJNasc & 5-XII-2005 & $\mathrm{P}$ & Cunha, G. \\
\hline 106119 & ABJMS & 13-IX-2004 & V & Silva, M.A. & 106736 & ABJMS & 5-XII-2005 & $\mathrm{P}$ & Cunha, G. \\
\hline
\end{tabular}


Table 1 (continuation)

\begin{tabular}{|c|c|c|c|c|c|c|c|c|c|}
\hline No HAS & $\begin{array}{l}\text { Sampling } \\
\text { station }\end{array}$ & Date & $\begin{array}{l}\text { Season } \\
\text { of year }\end{array}$ & Collector & $\mathrm{N}^{\circ} \mathrm{HAS}$ & $\begin{array}{l}\text { Sampling } \\
\text { station }\end{array}$ & Date & $\begin{array}{l}\text { Season } \\
\text { of year }\end{array}$ & Collector \\
\hline 106122 & ABJFS & 13-IX-2004 & $\mathrm{V}$ & Silva, M.A. & 106740 & ABJFS & 5-XII-2005 & $\mathrm{P}$ & Cunha, G. \\
\hline 106137 & ABJNasc & $7-X-2004$ & $\mathrm{O}$ & Cunha, G. & NR & ABJNasc & NR & NR & NR \\
\hline 106140 & ABJMS & $7-X-2004$ & $\mathrm{O}$ & Cunha, G. & 106770 & ABJMS & 9-I-2006 & $\mathrm{V}$ & Silva, S.M.A. \\
\hline 106143 & ABJFS & $7-X-2004$ & $\mathrm{O}$ & Cunha, G. & 106773 & ABJFS & 9-I-2006 & $\mathrm{V}$ & Silva, S.M.A. \\
\hline 106158 & ABJNasc & 8-XI-2004 & $\mathrm{O}$ & Silva, S.M.A. & 106780 & ABJNasc & 8-II-2006 & $\mathrm{V}$ & Silva, S.M.A. \\
\hline 106161 & ABJMS & 8-XI-2004 & $\mathrm{O}$ & Silva, S.M.A. & 106783 & ABJMS & 8-II-2006 & $\mathrm{V}$ & Silva, S.M.A. \\
\hline 106164 & ABJFS & 8-XI-2004 & $\mathrm{O}$ & Silva, S.M.A. & 106786 & ABJFS & 8-II-2006 & $\mathrm{V}$ & Silva, S.M.A. \\
\hline 106387 & ABJNasc & 6-XII-2004 & $\mathrm{O}$ & Silva, S.M.A. & 106806 & ABJNasc & 8-III-2006 & $\mathrm{V}$ & Silva, S.M.A. \\
\hline 106390 & ABJMS & 6-XII-2004 & $\mathrm{O}$ & Silva, S.M.A. & 106809 & ABJMS & 8-III-2006 & $\mathrm{V}$ & Silva, S.M.A. \\
\hline 106393 & ABJFS & 6-XII-2004 & $\mathrm{O}$ & Silva, S.M.A. & 106812 & ABJFS & 8-III-2006 & $\mathrm{V}$ & Silva, S.M.A. \\
\hline 106402 & ABJNasc & $11-I-2005$ & I & Cunha, G. & 106820 & ABJNasc & 11-IV-2006 & $\mathrm{O}$ & Juliano, V. \\
\hline 106405 & ABJMS & $11-I-2005$ & I & Cunha, G. & 106823 & ABJMS & 11-IV-2006 & $\mathrm{O}$ & Juliano, V. \\
\hline 106408 & ABJFS & $11-I-2005$ & I & Cunha, G. & 106826 & ABJFS & 11-IV-2006 & $\mathrm{O}$ & Juliano, V. \\
\hline 106423 & ABJNasc & $15-\mathrm{II}-2005$ & I & Silva, S.M.A. & 106840 & ABJNasc & $9-\mathrm{V}-2006$ & $\mathrm{O}$ & Silva, S.M.A. \\
\hline 106426 & ABJMS & $15-\mathrm{II}-2005$ & I & Silva, S.M.A. & 106843 & ABJMS & $9-\mathrm{V}-2006$ & $\mathrm{O}$ & Silva, S.M.A. \\
\hline 106429 & ABJFS & $15-\mathrm{II}-2005$ & I & Silva, S.M.A. & 106846 & ABJFS & $9-V-2006$ & $\mathrm{O}$ & Silva, S.M.A. \\
\hline 106443 & ABJNasc & 14-III-2005 & I & Silva, S.M.A. & 107032 & ABJNasc & 5-VI-2006 & $\mathrm{O}$ & Salomoni, S. \\
\hline 106446 & ABJMS & 14-III-2005 & I & Silva, S.M.A. & 107035 & ABJMS & $5-\mathrm{VI}-2006$ & $\mathrm{O}$ & Salomoni, S. \\
\hline 106449 & ABJFS & 14-III-2005 & I & Silva, S.M.A. & 107038 & ABJFS & 5-VI-2006 & $\mathrm{O}$ & Salomoni, S. \\
\hline 106546 & ABJNasc & 11-IV-2005 & $\mathrm{P}$ & Silva, S.M.A. & 107052 & ABJNasc & 11-VII-2006 & I & Rosa, Z.M. \\
\hline 106549 & ABJMS & 11-IV-2005 & $\mathrm{P}$ & Silva, S.M.A. & 107055 & ABJMS & 11-VII-2006 & I & Rosa, Z.M. \\
\hline 106552 & ABJFS & 11-IV-2005 & $\mathrm{P}$ & Silva, S.M.A. & 107058 & ABJFS & 11-VII-2006 & I & Rosa, Z.M. \\
\hline 106559 & ABJNasc & $12-V-2005$ & $\mathrm{P}$ & Cunha, G. & 107118 & ABJNasc & 8-VIII-2006 & I & Silva, S.M.A. \\
\hline 106562 & ABJMS & $12-V-2005$ & $\mathrm{P}$ & Cunha, G. & 107121 & ABJMS & 8-VIII-2006 & I & Silva, S.M.A. \\
\hline 106565 & ABJFS & $12-V-2005$ & $\mathrm{P}$ & Cunha, G. & 107124 & ABJFS & 8-VIII-2006 & I & Silva, S.M.A. \\
\hline 106576 & ABJNasc & 13-VI-2005 & $\mathrm{P}$ & Cunha, G. & 107131 & ABJNasc & 11-IX-2006 & I & Cunha, G. \\
\hline 106579 & ABJMS & 13-VI-2005 & $\mathrm{P}$ & Cunha, G. & 107134 & ABJMS & 11-IX-2006 & I & Cunha, G. \\
\hline 106582 & ABJFS & 13-VI-2005 & $\mathrm{P}$ & Cunha, G. & 107137 & ABJFS & 11-IX-2006 & I & Cunha, G. \\
\hline 106602 & ABJNasc & 12-VII-2005 & $\mathrm{V}$ & Silva, S.M.A. & 107225 & ABJNasc & $9-X-2006$ & $\mathrm{P}$ & Silva, S.M.A. \\
\hline 106605 & ABJMS & 12-VII-2005 & $\mathrm{V}$ & Silva, S.M.A. & 107228 & ABJMS & $9-X-2006$ & $\mathrm{P}$ & Silva, S.M.A. \\
\hline 106608 & ABJFS & 12-VII-2005 & $\mathrm{V}$ & Silva, S.M.A. & 107231 & ABJFS & $9-X-2006$ & $\mathrm{P}$ & Silva, S.M.A. \\
\hline 106617 & ABJNasc & 9-VIII-2005 & $\mathrm{V}$ & Silva, S.M.A. & 107238 & ABJNasc & 13-XI-2006 & $\mathrm{P}$ & Silva, S.M.A. \\
\hline 106620 & ABJMS & 9-VIII-2005 & $\mathrm{V}$ & Silva, S.M.A. & 107241 & ABJMS & 13-XI-2006 & $\mathrm{P}$ & Silva, S.M.A. \\
\hline 106623 & ABJFS & 9-VIII-2005 & $\mathrm{V}$ & Silva, S.M.A. & 107244 & ABJFS & 13-XI-2006 & $\mathrm{P}$ & Silva, S.M.A. \\
\hline 106646 & ABJNasc & 12-IX-2005 & $\mathrm{V}$ & Cunha, G. & 107251 & ABJNasc & 12-XII-2006 & $\mathrm{P}$ & Juliano, V. \\
\hline 106649 & ABJMS & 12-IX-2005 & $\mathrm{V}$ & Cunha, G. & 107254 & ABJMS & 12-XII-2006 & $\mathrm{P}$ & Juliano, V. \\
\hline 106652 & ABJFS & 12-IX-2005 & $\mathrm{V}$ & Cunha, G. & 107257 & ABJFS & 12-XII-2006 & $\mathrm{P}$ & Juliano, V. \\
\hline
\end{tabular}

Starmach 1983, Tell \& Conforti 1986, Wolowski 1998 and Shi et al. 1999) were used. Also, some recent papers by Alves-da-Silva (1988), Huszar et al. (1989), Menezes (1990), Cecy (1990), Xavier (1989, 1994), Alves-da-Silva \& Torres (1992), Ferreira \& Menezes (2000), Alves-da-Silva \& Bicudo (2002) and Alvesda-Silva \& Hahn (2004) were used.

\section{Results and Discussion}

One hundred and sixty two out of the 176 samples studied presented representatives of Lepocinclis Perty, allowing identification of 13 taxa of specific and infraspecific level, which were distributed among seven typical varieties, five varieties that are not the typical of their respective species and one taxonomic forma that is also not the typical.

\section{Division Euglenophyta \\ Class Euglenophyceae \\ Order Euglenales \\ Family Euglenaceae Genus Lepocinclis Perty 1852}

L. fusiformis (Carter) Lemmermann emend. Conrad var. fusiformis, Archiv für Protistenkunde 82(2): 225, fig. 30. 1934.

Figure 2 
Table 2. Variation range of abiotic features of the 3 Bom Jardim Creek portions where Lepocinclis was collected during the period 2002-2006. Zero $=$ not detected, $\mathrm{X}=$ average, $\delta=$ standard deviations.

\begin{tabular}{|c|c|c|c|c|c|c|c|c|}
\hline \multirow{2}{*}{$\begin{array}{l}\text { Taxa / Abiotic feature / Variation } \\
\text { range, average, deviation }\end{array}$} & \multicolumn{2}{|c|}{ Amonium $\left(\mu \mathrm{g} \mathrm{L}^{-1}\right)$} & \multirow[b]{2}{*}{$\mathrm{X}$} & \multicolumn{3}{|c|}{ Conductivity $\left(\mu \mathrm{S} \mathrm{cm}^{-1}\right)$} & \multirow[b]{2}{*}{$\mathrm{X}$} & \multirow[b]{2}{*}{$\delta$} \\
\hline & Minimum & Maximum & & $\delta$ & Minimum & Maximum & & \\
\hline L. fusiformis var. fusiformis & 0 & 260 & 130 & 184 & 13,2 & 1450 & 732 & 1016 \\
\hline L. fusiformis var. amphirynchus & 0 & 250 & 125 & 177 & 22,2 & 603 & 313 & 411 \\
\hline L. fusiformis var. minor & 0 & 220 & 110 & 156 & 180 & 549 & 365 & 261 \\
\hline L. ovum var. ovum & 0 & 250 & 125 & 177 & 13,2 & 762 & 388 & 529 \\
\hline L. ovum var. dimidio-minor & 0 & 260 & 130 & 184 & 13,2 & 1092 & 553 & 763 \\
\hline L. ovum var. globula & 40 & 220 & 130 & 127 & 45,4 & 398 & 222 & 249 \\
\hline L. playfairiana & 0 & 60 & 30 & 42 & 62 & 249 & 156 & 132 \\
\hline L. salina var. salina & 0 & 260 & 130 & 184 & 17,2 & 1450 & 734 & 1013 \\
\hline L. salina f. obtusa & 0 & 260 & 130 & 184 & 13,2 & 670 & 342 & 464 \\
\hline L. salina var. vallicauda & 0 & 80 & 40 & 57 & 38,2 & 762 & 400 & 512 \\
\hline L. steinii & 0 & 150 & 75 & 106 & 44,3 & 762 & 403 & 507 \\
\hline L. truncata & 0 & 250 & 125 & 177 & 17,2 & 736 & 377 & 508 \\
\hline L. turbiniformis & 0 & 100 & 50 & 71 & 38,5 & 98 & 68 & 42 \\
\hline \multirow{2}{*}{$\begin{array}{l}\text { Taxa / Abiotic feature / Variation } \\
\text { range, average, deviation }\end{array}$} & \multicolumn{2}{|c|}{ DBO5 $\left(\mathrm{mg} \mathrm{L}^{-1}\right)$} & \multicolumn{6}{|c|}{ Org. Matter $\left(\mathrm{mg} \mathrm{L}^{-1}\right)$} \\
\hline & Minimum & Maximum & $\mathrm{X}$ & $\delta$ & Minimum & Maximum & $\mathrm{X}$ & $\delta$ \\
\hline L. fusiformis var. fusiformis & 0,3 & 5,5 & 3 & 4 & 2,3 & 12 & 7 & 7 \\
\hline L. fusiformis var. amphirynchus & 1,1 & 5,3 & 3 & 3 & 4,5 & 11,3 & 8 & 5 \\
\hline L. fusiformis var. minor & 2,8 & 3,2 & 3 & 0 & 7,7 & 9 & 8 & 1 \\
\hline L. ovum var. ovum & 0,6 & 8 & 4 & 5 & 3,1 & 11,3 & 7 & 6 \\
\hline L. ovum var. dimidio-minor & 0,3 & 5,3 & 3 & 4 & 3,1 & 11,3 & 7 & 6 \\
\hline L. ovum var. globula & 1,2 & 2,5 & 2 & 1 & 7 & 8,9 & 8 & 1 \\
\hline L. playfairiana & 2,2 & 5,3 & 4 & 2 & 6,2 & 11 & 9 & 3 \\
\hline L. salina var. salina & 0,3 & 8 & 4 & 5 & 2,3 & 12 & 7 & 7 \\
\hline L. salina f. obtusa & 0,6 & 5,3 & 3 & 3 & 4,5 & 11 & 8 & 5 \\
\hline L. salina var. vallicauda & 0,4 & 5,3 & 3 & 3 & 5,2 & 11 & 8 & 4 \\
\hline L. steinii & 1,5 & 5,5 & 4 & 3 & 4,7 & 10 & 7 & 4 \\
\hline L. truncata & 0,3 & 5,3 & 3 & 4 & 4,4 & 11 & 8 & 5 \\
\hline L. turbiniformis & 0,5 & 5 & 3 & 3 & 5,3 & 7,5 & 6 & 2 \\
\hline \multirow{2}{*}{$\begin{array}{l}\text { Taxa / Abiotic feature / Variation } \\
\text { range, average, deviation }\end{array}$} & \multicolumn{2}{|c|}{ Nitrite $\left(\mu \mathrm{g} \mathrm{L}^{-1}\right)$} & \multicolumn{6}{|c|}{ Ortophosphate $\left(\mu \mathrm{g} \mathrm{L}^{-1}\right)$} \\
\hline & Minimum & Maximum & $\mathrm{X}$ & $\delta$ & Minimum & Maximum & $\mathrm{X}$ & $\delta$ \\
\hline L. fusiformis var. fusiformis & 0 & 8 & 4 & 6 & 0 & 1440 & 720 & 1018 \\
\hline L. fusiformis var. amphirynchus & 0 & 7 & 4 & 5 & 0 & 1440 & 720 & 1018 \\
\hline L. fusiformis var. minor & 0 & 5 & 3 & 4 & 0 & 680 & 340 & 481 \\
\hline L. ovum var. ovum & 0 & 7 & 4 & 5 & 0 & 850 & 425 & 601 \\
\hline L. ovum var. dimidio-minor & 0 & 18 & 9 & 13 & 0 & 1440 & 720 & 1018 \\
\hline L. ovum var. globula & 0 & 1 & 1 & 1 & 90 & 460 & 275 & 262 \\
\hline L. playfairiana & 0 & 7 & 4 & 5 & 20 & 950 & 485 & 658 \\
\hline L. salina var. salina & 0 & 38 & 19 & 27 & 0 & 1470 & 735 & 1039 \\
\hline L. salina f. obtusa & 0 & 8 & 4 & 6 & 0 & 1440 & 720 & 1018 \\
\hline L. salina var. vallicauda & 0 & 0 & 0 & 0 & 0 & 850 & 425 & 601 \\
\hline L. steinii & 0 & 7 & 4 & 5 & 0 & 850 & 425 & 601 \\
\hline L. truncata & 0 & 8 & 4 & 6 & 0 & 1470 & 735 & 1039 \\
\hline L. turbiniformis & 0 & 4 & 2 & 3 & 20 & 130 & 75 & 78 \\
\hline
\end{tabular}


Table 2 (continuation)

\begin{tabular}{|c|c|c|c|c|c|c|c|c|}
\hline \multirow{2}{*}{$\begin{array}{l}\text { Taxa / Abiotic feature / Variation } \\
\text { range, average, deviation }\end{array}$} & \multicolumn{2}{|c|}{$\mathrm{DO}\left(\mathrm{mg} \mathrm{L}^{-1}\right)$} & \multicolumn{6}{|c|}{$\%$ DO } \\
\hline & Minimum & Maximum & $\mathrm{X}$ & $\delta$ & Minimum & Maximum & $\mathrm{X}$ & $\delta$ \\
\hline L. fusiformis var. fusiformis & 2,2 & 9,3 & 6 & 5 & 27,1 & 95,2 & 61 & 48 \\
\hline L. fusiformis var. amphirynchus & 2,8 & 9,2 & 6 & 5 & 33,9 & 96,6 & 65 & 44 \\
\hline L. fusiformis var. minor & 2 & 7,6 & 5 & 4 & 23,3 & 90,3 & 57 & 47 \\
\hline L. ovum var. ovum & NM & 9,2 & $\mathrm{NM}$ & $\mathrm{NM}$ & $\mathrm{NM}$ & 98,7 & 99 & \\
\hline L. ovum var. dimidio-minor & NM & 8,9 & NM & NM & NM & 98,4 & 98 & \\
\hline L. ovum var. globula & 4,8 & 8,2 & 7 & 2 & 46 & 81,3 & 64 & 25 \\
\hline L. playfairiana & 2,8 & 7,2 & 5 & 3 & 33,9 & 83,4 & 59 & 35 \\
\hline L. salina var. salina & NM & 9,2 & NM & NM & NM & 98,7 & 99 & \\
\hline L. salina f. obtusa & NM & 8,7 & NM & NM & NM & 96,6 & 97 & \\
\hline L. salina var. vallicauda & 3,4 & 6,7 & 5 & 2 & 38,7 & 92,6 & 66 & 38 \\
\hline L. steinii & 2,5 & 8,7 & 6 & 4 & 29,1 & 84,4 & 57 & 39 \\
\hline L. truncata & 2,2 & 9 & 6 & 5 & 27,1 & 96,6 & 62 & 49 \\
\hline L. turbiniformis & 2,5 & 8,6 & 6 & 4 & 33,1 & 90,8 & 62 & 41 \\
\hline \multirow{2}{*}{$\begin{array}{l}\text { Taxa / Abiotic feature / Variation } \\
\text { range, average, deviation }\end{array}$} & \multicolumn{2}{|c|}{ Nitrate $\left(\mu g \mathrm{~L}^{-1}\right)$} & \multicolumn{6}{|c|}{ Temperatura $\left({ }^{\circ} \mathrm{C}\right)$ water } \\
\hline & Minimum & Maximum & $X$ & $\delta$ & Minimum & Maximum & $X$ & $\delta$ \\
\hline L. fusiformis var. fusiformis & 0 & 800 & 400 & 566 & 9,7 & 33,6 & 22 & 17 \\
\hline L. fusiformis var. amphirynchus & 0 & 800 & 400 & 566 & 15 & 33,6 & 24 & 13 \\
\hline L. fusiformis var. minor & 0 & 200 & 100 & 141 & 18,1 & 24 & 21 & 4 \\
\hline L. ovum var. ovum & 0 & 900 & 450 & 636 & 15 & 31,8 & 23 & 12 \\
\hline L. ovum var. dimidio-minor & 0 & 1700 & 850 & 1202 & 9,7 & 33,6 & 22 & 17 \\
\hline L. ovum var. globula & 0 & 200 & 100 & 141 & 15 & 25,6 & 20 & 7 \\
\hline L. playfairiana & 0 & 800 & 400 & 566 & 18,1 & 30,6 & 24 & 9 \\
\hline L. salina var. salina & 0 & 1700 & 850 & 1202 & 9,7 & 33,6 & 22 & 17 \\
\hline L. salina f. obtusa & 0 & 1200 & 600 & 849 & 13 & 30,6 & 22 & 12 \\
\hline L. salina var. vallicauda & 0 & 700 & 350 & 495 & 19,3 & 29,9 & 25 & 7 \\
\hline L. steinii & 0 & 800 & 400 & 566 & 14,4 & 30,2 & 22 & 11 \\
\hline L. truncata & 0 & 1100 & 550 & 778 & 13,1 & 33,6 & 23 & 14 \\
\hline L. turbiniformis & 0 & 300 & 150 & 212 & 18,7 & 30,2 & 24 & 8 \\
\hline \multirow{2}{*}{$\begin{array}{l}\text { Taxa / Abiotic feature / Variation } \\
\text { range, average, deviation }\end{array}$} & \multicolumn{2}{|c|}{$\mathrm{pH}$} & \multicolumn{6}{|c|}{ Silicate $\left(\mathrm{mg} \mathrm{L}^{-1}\right)$} \\
\hline & Minimum & Maximum & $X$ & $\delta$ & Minimum & Maximum & $X$ & $\delta$ \\
\hline L. fusiformis var. fusiformis & 5,6 & 7,1 & 6 & 1 & 1,3 & 20,6 & 11 & 14 \\
\hline L. fusiformis var. amphirynchus & 6,2 & 7,1 & 7 & 1 & 1,3 & 16,3 & 9 & 11 \\
\hline L. fusiformis var. minor & 6,5 & 7,1 & 7 & 0 & 5,1 & 12,8 & 9 & 5 \\
\hline L. ovum var. ovum & 5,8 & 7,1 & 6 & 1 & 1,3 & 16,5 & 9 & 11 \\
\hline L. ovum var. dimidio-minor & 5,6 & 7,1 & 6 & 1 & 1,3 & 23,1 & 12 & 15 \\
\hline L. ovum var. globula & 6,3 & 6,6 & 6 & 0 & 13,2 & 15 & 14 & 1 \\
\hline L. playfairiana & 6,4 & 6,9 & 7 & 0 & 10 & 16,3 & 13 & 4 \\
\hline L. salina var. salina & 5,6 & 7,1 & 6 & 1 & 1,3 & 23,1 & 12 & 15 \\
\hline L. salina f. obtusa & 6 & 7,5 & 7 & 1 & 5,7 & 19,2 & 12 & 10 \\
\hline L. salina var. vallicauda & 6,2 & 7,1 & 7 & 1 & 7,7 & 16,5 & 12 & 6 \\
\hline L. steinii & 6,3 & 7 & 7 & 0 & 5,7 & 16,5 & 11 & 8 \\
\hline L. truncata & 5,6 & 7,1 & 6 & 1 & 5,8 & 19,2 & 13 & 9 \\
\hline L. turbiniformis & 6,3 & 6,8 & 7 & 0 & 1,3 & 11,2 & 6 & 7 \\
\hline
\end{tabular}


Cell lemon-shaped to fusiform, 35-40.5 $\mu \mathrm{m}$ long., 24-28 $\mu \mathrm{m}$ broad, $\mathrm{Rl} / \mathrm{b}=1.3-1.6$; anterior pole with or without an obtuse nipple, opening of apical channel; posterior pole slightly acuminated; rigid pellicle, hyaline, spirally striated to the left, striae very delicate; numerous chloroplasts, discoid to ellipsoid, ca. $2.8 \mu \mathrm{m}$ diam.; paramylon bodies 2, lateral, ring-shaped.

Material studied: HAS35999, HAS103156, HAS103249, HAS103250, HAS103254, HAS103394, HAS103397, HAS103458, HAS103524, HAS103665, HAS103668, HAS103690, HAS103693, HAS103696, HAS103833, HAS103836, HAS103856, HAS103859, HAS103862, HAS103952, HAS103993, HAS103996, HAS103999, HAS104014, HAS104017, HAS104020, HAS104045, HAS104283, HAS104319, HAS104522, HAS104528, HAS104564, HAS104582, HAS104585, HAS104588, HAS104767, HAS104770, HAS104773, HAS104786, HAS104804, HAS104807, HAS104810, HAS104824, HAS104827, HAS104847, HAS104850, HAS106101, HAS106137, HAS106164, HAS106390, HAS106393, HAS106402, HAS106405, HAS106423, HAS106426, HAS106429, HAS106446, HAS106449, HAS106565, HAS106718, HAS106721, HAS106780, HAS106812, HAS106823, HAS106846, HAS107055, HAS107058, HAS107121, HAS107137, HAS107231 and HAS107257.

Geographical distribution in Brazil: Amazonas, Distrito Federal, Mato Grosso, Paraná, Rio de Janeiro, Rio Grande do Sul, Rondônia, São Paulo and Santa Catarina.

L. fusiformis (Carter) Lemmermann emend. Conrad var. amphirhynchus Nygaard, K. Dansk Vid. Selsk. Biol. Skr., 7(1): 167, fig. 101. 1949.

Figures 3-4

Cell lemon-shaped, 29-31.5 $\mu \mathrm{m}$ long., 21.5-23 $\mu \mathrm{m}$ broad, $\mathrm{Rl} / \mathrm{b}=1.3-1.4$; anterior pole with nipple obtuse prominent ca. of $4 \mu \mathrm{m}$ long. by $5 \mu \mathrm{m}$ broad, caudal process reduced to a nipple; rigid pellicle, spirally striated to the left, striae very delicate; numerous chloroplasts, discoid to ellipsoid, 2,0- $2.8 \mu \mathrm{m}$ diam.; paramylon bodies 2, lateral, ring-shaped.

The variety differs from the typical of the species by the fact that the anterior pole is more prominent.

Material studied: HAS 103249 , HAS 103250 , HAS103856, HAS103862, HAS103996, HAS104020, HAS104045, HAS104283, HAS104319, HAS104522, HAS104528, HAS104564, HAS104770, HAS104773, HAS104585, HAS106101, HAS106122, HAS106408,
HAS106428, HAS106429, HAS106446, HAS106449, HAS106552, HAS 106565 and HAS 106738.

Geographical distribution in Brazil: Amazonas, Paraná, Rio Grande do Sul and Rio de Janeiro.

L. fusiformis (Carter) Lemmermann emend. Conrad var. minor Chu, Sinensia 7: 286, fig. 21-22. 1936.

Figures 5-6

Cell broadly elliptical, 16-21 $\mu \mathrm{m}$ long., 14-17 $\mu \mathrm{m}$ broad, $\mathrm{Rl} / \mathrm{b}=1.1-1.2$; anterior pole without an obtuse nipple, opening of apical channel; posterior pole slightly acuminated; rigid pellicle, hyaline, striae very delicate difficult to see; numerous chloroplasts, discoid ca. $2.0 \mu \mathrm{m}$ diam.; paramylon bodies 2 , lateral, ring-shaped.

The variety differs from the typical of the species in its smaller cell dimensions and without caudal process.

Material studied: HAS103391, HAS106449, HAS106806 and HAS107231.

Geographical distribution in Brazil: Rio Grande do Sul.

L. ovum (Ehrenberg) Lemmermann var. ovum,

Kryptogamenflora Brandenburg 3: 504, fig. 13. 1910. Figures 7-9

Cell elliptical to oblong-elliptical, 30-40 $\mu \mathrm{m}$ long., 15-25 $\mu \mathrm{m}$ broad, $\mathrm{Rl} / \mathrm{b}=1.5-2.6$; anterior pole rounded, opening of apical channel, posterior pole abruptly narrowed into a short, colourless, conical caudal process, 2.5-4.6 $\mu \mathrm{m}$ long.; rigid pellicle, spirally striated to the left; numerous chloroplasts, parietal, discoid, ca. $2.0 \mu \mathrm{m}$ diam.; paramylon bodies 2 , lateral, ring-shaped, sometimes elongate, overlapping each other along the longitudinal cell axis, 11-14 $\mu \mathrm{m}$ long.

Material studied: HAS 103156, HAS 103202 , HAS103457, HAS103458, HAS103665, HAS103693, HAS103696, HAS103830, HAS103859, HAS103862, HAS103946, HAS104528, HAS104543, HAS104564, HAS104582, HAS104585, HAS104767, HAS104770, HAS104807, HAS106116, HAS106122, HAS106137, HAS106158, HAS106387, HAS106402, HAS106405, HAS106423, HAS106426, HAS106429, HAS106443, HAS106446, HAS106552, HAS106565, HAS106734, HAS106780, HAS106806, HAS106840, HAS107118, HAS107131 and HAS107244.

Geographical distribution in Brazil: Amazonas, Goiás, Mato Grosso, Paraná, Rio Grande do Sul, Rio de Janeiro, Rondônia, Santa Catarina, São Paulo and Tocantins. 
L. ovum (Ehrenberg) Lemmermann var. dimidiominor Deflandre, Bulletin de la Société botanique de France 24(4): 1121, fig. 25-28. 1924.

Figures 10-11

Cell narrowly elliptical to elliptical, 16-21 $\mu \mathrm{m}$ long., 9-16 $\mu \mathrm{m}$ broad, $\mathrm{Rl} / \mathrm{b}=1.3-1.8$; anterior pole rounded, posterior pole attenuated into a caudal process; caudal process reduced to a nipple, ca. $1 \mu \mathrm{m}$ long; flagellum as long as the cell.

L. ovum var. dimidio-minor differs from the type of the species in its smaller cell dimensions and in the caudal process reduced to a nipple about $1 \mu \mathrm{m}$ long.

Material studied: HAS 103156, HAS103163, HAS103195, HAS103202, HAS103250, HAS103254, HAS103394, HAS103397, HAS103458, HAS103646, HAS103665, HAS103668, HAS103671, HAS103690, HAS103693, HAS103696, HAS103830, HAS103833, HAS103836, HAS103856, HAS103859, HAS103862, HAS103946, HAS103949, HAS103993, HAS103996, HAS103999, HAS104014, HAS104017, HAS104020, HAS104039, HAS104045, HAS104070, HAS104319, HAS104522, HAS104528, HAS104543, HAS104549, HAS104561, HAS104564, HAS104582, HAS104585, HAS104770, HAS104783, HAS104807, HAS104827, HAS104847, HAS104850, HAS106119, HAS106137, HAS106143, HAS106158, HAS106165, HAS106387, HAS106390, HAS106402, HAS106405, HAS106408, HAS106423, HAS106426, HAS106429, HAS106443, HAS106449, HAS106546, HAS106549, HAS106559, HAS106562, HAS106565, HAS106620, HAS106706, HAS106709, HAS106716, HAS106718, HAS106721, HAS106734, HAS106770, HAS106773, HAS106780, HAS106786, HAS106806, HAS106809, HAS106840, HAS107038, HAS107055, HAS107124, HAS107131, HAS107134, HAS107231, HAS107238, HAS107241, HAS107251, HAS107254 and HAS107257.

Geographical distribution in Brazil: Amazonas, Distrito Federal, Goiás, Mato Grosso, Paraná, Rio Grande do Sul, Rio de Janeiro, Santa Catarina, São Paulo and Tocantins.

L. ovum (Ehrenberg) Lemmermann var. globula (Perty) Lemmermann, Kryptogamenflora Brandenburg 3(4): 505. 1910.

Figures 12-13

Cell subglobose, 23.5-30 $\mu \mathrm{m}$ long., 23.5-27 $\mu \mathrm{m}$ broad, $\mathrm{Rl} / \mathrm{b}=1.0-1.3$; anterior pole rounded, opening of apical channel, posterior pole abruptly narrowed into a short, colourless, conical caudal process,
2.3-3.1 $\mu \mathrm{m}$ long; rigid pellicle, spirally striated to the left; numerous chloroplasts, parietal, discoid, ca. $2.3 \mu \mathrm{m}$ diam.; paramylon bodies 2, lateral, ring-shaped, sometimes elongate, overlapping each other along the longitudinal cell axis, ca. $13 \mu \mathrm{m}$ long.

The variety differs from the typical of the species by cell subglobose.

Material studied: HAS103156, HAS104546, HAS 104767, HAS 106122 , HAS 106387 and HAS106449.

Geographical distribution in Brazil: Amazonas, Mato Grosso, Paraná, Pernambuco, Federal District, Rio Grande do Sul, Rio de Janeiro and São Paulo.

L. playfairiana Deflandre var. playfairiana, Annales de Protistologie. 2: 16, fig. 23. 1929.

Figures 14-15

Cell broadly fusiform to elliptical, 47-50 $\mu \mathrm{m}$ long., 20.5-24 $\mu \mathrm{m}$ broad, $\mathrm{Rl} / \mathrm{b}=2.0-2.4$; anterior pole asymetric, with a boss reminding beak; posterior pole, colourless, conical caudal process slightly acuminated, straight, 7.5-11 $\mu \mathrm{m}$ long., pellicle smooth; numerous chloroplasts, parietal, discoid, ca. of $3.0 \mu \mathrm{m}$ diam.; paramylon bodies 2, lateral, ring-shaped; emergent flagellum $1 / 2$ of cell length.

Material studied: HAS103156, HAS104528, HAS 104582 , HAS 104585 , HAS 106408 and HAS 106565.

Geographical distribution in Brazil: Amazonas and Rio Grande do Sul.

L. salina Fritsch var. salina, New Phytologist 13: 351, fig. 3a-b, e. 1914.

Figure 16

Cell broad ovoid to ovoid, 38-52 $\mu \mathrm{m}$ long., 29-45 $\mu \mathrm{m}$ broad, $\mathrm{Rl} / \mathrm{b}=1.1-1.5$; circular in crosssection; anterior pole rounded, opening of channel subapical, produced into a deep, oblique, lateral depression; caudal process usually absent; rigid pellicle, colourless, spirally striated to the right; numerous chloroplasts, parietal, discoid, ca. of $1.5 \mu \mathrm{m}$ diam.; paramylon bodies numerous, discoid or globose, never ring-shaped, 3.0-3.5 $\mu \mathrm{m}$ diam., emergent flagellum 1/5 of cell length.

Material studied: HAS35999, HAS 103156 , HAS103163, HAS103188, HAS103202, HAS103249, HAS103250, HAS103254, HAS103397, HAS103457, HAS103458, HAS103527, HAS103640, HAS103665, 


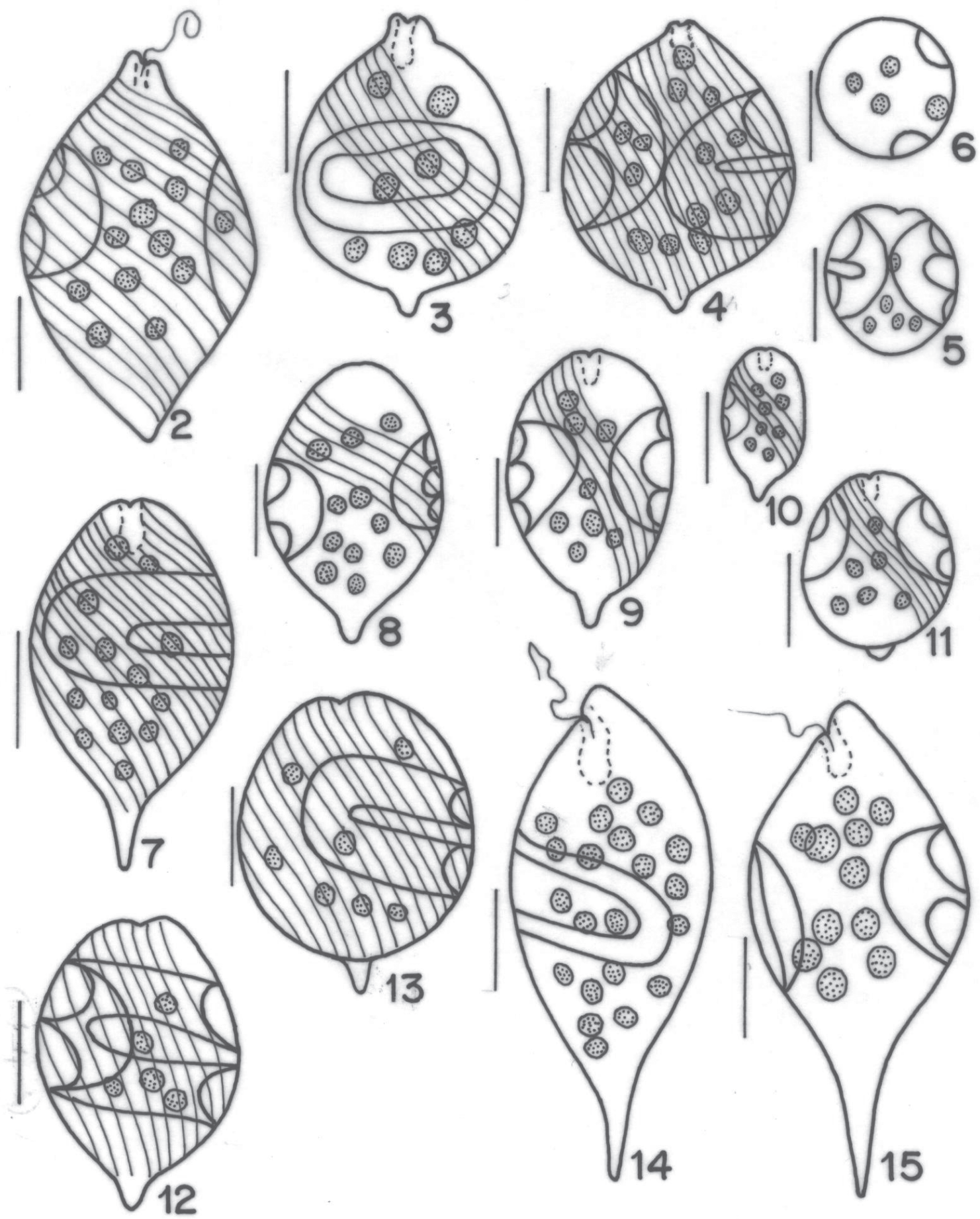

Figures 2-14. Taxa belonging to class Euglenophyceae. 2. L. fusiformis (Carter) Lemmermann emend. Conrad var. fusiformis. 3-4. L. fusiformis (Carter) Lemmermann emend. Conrad var. amphirhynchus. 5-6. L. fusiformis (Carter) Lemmermann emend. Conrad var. minor Chu. 6. apical view. 7-9. L. ovum (Ehrenberg) Lemmermann var. ovum. 10-11. L. ovum (Ehrenberg) Lemmermann var. dimidiominor. 12-13. L. ovum (Ehrenberg) Lemmermann var. globula (Perty) Lemmermann. 14-15. L. playfairiana Deflandre var. playfairiana. Scale bars $=10 \mu \mathrm{m}$. 
HAS103668, HAS103671, HAS103690, HAS103693, HAS103696, HAS103830, HAS103833, HAS103836, HAS103856, HAS103859, HAS103862, HAS103946, HAS103949, HAS103952, HAS103993, HAS103999, HAS104014, HAS104017, HAS104020, HAS104042, HAS104064, HAS104067, HAS104070, HAS104280, HAS104298, HAS104301, HAS104319, HAS104322, HAS104522, HAS104528, HAS104543, HAS104546, HAS104549, HAS104561, HAS104564, HAS104567, HAS104582, HAS104585, HAS104588, HAS104767, HAS104770, HAS104773, HAS104783, HAS104786, HAS104789, HAS104804, HAS104807, HAS104810, HAS104821, HAS104824, HAS104844, HAS104850, HAS106095, HAS106098, HAS106101, HAS106116, HAS106119, HAS106122, HAS106137, HAS106140, HAS106143, HAS106158, HAS106161, HAS106164, HAS106387, HAS106390, HAS106393, HAS106402, HAS106405, HAS106408, HAS106423, HAS106426, HAS106429, HAS106443, HAS106446, HAS106546, HAS106549, HAS106552, HAS106559, HAS106562, HAS106565, HAS106576, HAS106579, HAS106582, HAS106602, HAS106605, HAS106608, HAS 106617 , HAS106620, HAS106623, HAS106649, HAS106652, HAS106703, HAS106706, HAS106709, HAS106716, HAS106718, HAS106738, HAS106740, HAS106770, HAS106773, HAS106780, HAS106783, HAS106806, HAS106809, HAS106812, HAS106820, HAS106823, HAS106826, HAS106846, HAS107032, HAS106035, HAS 107038 , HAS 107055 , HAS 107058 , HAS 107118 , HAS107131, HAS107137, HAS107225, HAS107228, HAS107231, HAS107238, HAS107241, HAS107244, HAS107251, HAS107254 and HAS107257.

Geographical distribution in Brazil: Amazonas, Distrito Federal, Goiás, Mato Grosso, Paraná, Rio Grande do Sul, Rio de Janeiro, Rondônia, Santa Catarina, São Paulo and Tocantins.

L. salina Fritsch var. salina f. obtusa (HuberPestalozzi) Conrad, Mémoires du Musée royal d'histoire naturelle de Belgique 2(1): 63, fig. 58. 1935. Figure 17

Cell broadly elliptical to ovoid, $42-48 \mu \mathrm{m}$ long., 26-32 $\mu \mathrm{m}$ broad, $\mathrm{Rl} / \mathrm{b}=1.4-1.8$; anterior pole rounded, posterior pole attenuated into a colourless, straight, conical-truncate caudal process, ca. $3.5 \mu \mathrm{m}$ long.

L. salina var. salina f. obtusa differs from the typical variety of the species by present a caudal process conical-truncate.

Material studied: HAS35999, HAS103156,
HAS106188, HAS103202, HAS103249, HAS103250, HAS103254, HAS103397, HAS103665, HAS103690, HAS103859, HAS 103862 HAS103949, HAS103952, HAS103993, HAS103996, HAS104020, HAS104045, HAS104319, HAS104528, HAS104543, HAS104546, HAS104564, HAS104582, HAS104585, HAS104588, HAS104810, HAS104821, HAS106137, HAS106158, HAS106393, HAS106443, HAS106446, HAS106546, HAS106549, HAS106565, HAS106576, HAS106608, HAS106703, HAS106770, HAS106780, HAS106783, HAS 106786, HAS 106809 , HAS 106820 and HAS 107137.

Geographical distribution in Brazil: Rio Grande do Sul and Santa Catarina.

L. salina Fritsch var. vallicauda Conrad, Mémoires du Musée royal d'histoire naturelle de Belgique 2(1): 63.1935.

Figure 18

Cell broadly elliptical to ovoid, 61-63 $\mu \mathrm{m}$ long., ca. $33 \mu \mathrm{m}$ broad, $\mathrm{Rl} / \mathrm{b}=1.8-1.9$; anterior pole rounded, opening of subapical channel; caudal process conicalacute and slightly curved, 8.5 to $9.5 \mu \mathrm{m}$ long.; rigid pellicle, colourless, spirally striated to the right; numerous chloroplasts, parietal, discoid, ca. $2.0 \mu \mathrm{m}$ diam.; paramylon bodies 2, lateral, ring-shaped, 17-20 $\mu \mathrm{m}$ diam.; emergent flagellum $1 / 2$ of cell length.

L. salina var. vallicauda differs from the typical variety of the species by present conical-acute and slightly curved caudal process.

Material studied: HAS35999, HAS 103202 , HAS103250, HAS104546, HAS104564, HAS104585, HAS104786, HAS104589, HAS106546, HAS106549, HAS 106823 and HAS107244.

Geographical distribution in Brazil: Minas Gerais, Rio Grande do Sul and São Paulo.

L. steinii Lemmermann emend. Conrad, Archiv für Protistenkunde 82(2): 206-207, fig. 4-5. 1934. Figures 19-20

Cell fusiform to elliptical, 22-25 $\mu \mathrm{m}$ long., 9.5-14 $\mu \mathrm{m}$ broad, $\mathrm{R} 1 / \mathrm{b}=1.6-2.5$; anterior pole rounded, opening of apical channel; posterior pole abruptly narrowed into a short, colourless, conical caudal process, 1.9-2.1 $\mu \mathrm{m}$ long.; rigid pellicle, striated longitudinal; numerous chloroplasts, parietal, discoid, 1.3-2.3 $\mu \mathrm{m}$ diam.; paramylon bodies 2 , lateral, ringshaped, $10-12 \mu \mathrm{m}$ long. 
Material studied: HAS103668, HAS 104017 , HAS106158, HAS106402, HAS106405, HAS106423, HAS106426, HAS106565, HAS106605, HAS106812 and HAS107244.

Geographical distribution in Brazil: Rio Grande do Sul, Rio de Janeiro and São Paulo.

L. truncata Da Cunha var. truncata, Memórias do Instituto Oswaldo Cruz 6(3): 170, pl. 24, fig. 1. 1914. Figures 21-22

Cell rhomboidal to 5-angular, 38-51 $\mu \mathrm{m}$ long., 30-47 $\mu \mathrm{m}$ broad, $\mathrm{Rl} / \mathrm{b}=1.1-1.3$; anterior pole truncate, opening of apical channel, posterior pole rounded; rigid pellicle, spirally striated to the left; numerous chloroplasts, parietal, discoid, ca. $2.5 \mu \mathrm{m}$ diam.; paramylon bodies 2, lateral, ring-shaped; emergent flagellum $1 / 2$ of cell length.

Material studied: HAS103163, HAS103202, HAS103249, HAS103397, HAS103527, HAS103621, HAS103671, HAS103668, HAS103693, HAS103830, HAS103833, HAS103856, HAS103859, HAS103862, HAS103993, HAS104017, HAS104042, HAS104045, HAS104319, HAS104522, HAS104528, HAS104549, HAS104582, HAS104585, HAS106767, HAS104773, HAS106402, HAS106408, HAS106426, HAS106429, HAS106446, HAS106562, HAS106620, HAS106709, HAS106721, HAS106734, HAS106770, HAS106773, HAS106812, HAS106823, HAS106780, HAS106783, HAS106786, HAS106809, HAS106820, HAS106823 and HAS 106826.

Geographical distribution in Brazil: Rio Grande do Sul and Santa Catarina.

L. turbiniformis Deflandre, Bulletin du Muséum d'Histoire naturelle de Paris 6: 422. 1926.

Figures 23-24

Cell turbiniform, 33-40 $\mu \mathrm{m}$ long., 20-22 $\mu \mathrm{m}$ broad, $\mathrm{Rl} / \mathrm{b}=1.5-2.0$; circular in cross-section; anterior pole rounded, opening of apical channel; posterior pole abruptly narrowed in conical caudal process, straigt, 7.5-11.5 $\mu \mathrm{m}$ long.; rigid pellicle, spirally striated to the left; numerous chloroplasts, parietal, discoid, ca. $2.3 \mu \mathrm{m}$ diam.; paramylon bodies 2, lateral, ring-shaped.

Material studied: HAS104770, HAS 104804 , HAS103671, HAS103402, HAS104298, HAS104402, HAS104405 and HAS107244.

Geographical distribution in Brazil: Mato Grosso, Rio Grande do Sul and Rio de Janeiro.
As mentioned before, Marins et al. (2003) proposed the transference of some Euglena species of Section Rigidae Pringsheim (1953) to Lepocinclis, despite of Euglena acus be usually straight, spindleshaped, but may assume C, J, or S shapes, and E. spirogyra and E. oxyuris var. fusca may vary in shape from spindle-shaped to rounded. Also, these taxa have cell morphology and the shape (rod-shaped) of paramylum granules considerably different from those of Lepocinclis. Among Lepocinclis distinctive features in Conrad $(1934,1935)$ are the thick rigid pellicle, the elliptical, fusiform to ovoid cell shape, with helicoidal striae, the presence of lateral, ring-shaped paramylum granules and the lack of pyrenoids. All those characteristics are well fundamented and do work; for what reason we presently do not accept the transference of the above mentioned Euglena to Lepocinclis.

All 13 taxa presently identified have already been cited for the state of Rio Grande do Sul, with emphasis to Lepocinclis fusiformis var. fusiformis, L. ovum var. ovum, L. ovum var. dimidio-minor and L. salina var. salina that are widely distributed in Brazil.

Lepocinclis salina var. salina was the widest distributed species in the Bom Jardim Creek during the five years period of present sampling, occurring in 142 sample units studied, and was immediately followed by L. ovum var. dimidio-minor present in 93 sample units and L. fusiformis var. fusiformis in 72 sample units. These three taxa were characterized by tolerating a wide variation of environmental conditions (table 2), especially of water temperature that varied from 9.7 to $33.6{ }^{\circ} \mathrm{C}$, ammonium from not detected by the method used to $260 \mu \mathrm{g} \mathrm{L}^{-1}$, organic matter from 2.3 to $12 \mathrm{mg} \mathrm{L}^{-1}$, orthophosphate from not detected by the method used to $1,470 \mu \mathrm{g} \mathrm{L}^{-1}$ and conductivity from 13.2 to $1450 \mu \mathrm{S} \mathrm{cm}^{-1}$. Despite of have already been registered for several other aquatic systems of Rio Grande do Sul state, L. salina var. salina occurred in $81 \%$ of total samples collected from Bom Jardim creek, as well as during many months with a high number of individual specimens per preparation (>30 ind preparation).

Lepocinclis ovum var. globula, L. playfairiana and $L$. turbiniformis were collected from acid water, whereas $L$. steinii from both acid and neutral waters, and all remaining taxa from acid to alkaline water (table 2).

According to Wetzel (2001), euglenophytes live best in shallow, organic matter rich water. Lepocinclis 
was collected from water with organic matter varying from oligosaprobic $\left(2.3 \mathrm{mg} \mathrm{L}^{-1}\right)$ to $\beta$-mesosaprobic (12 $\mathrm{mg} \mathrm{L}^{-1}$ ), according to Hamm (1969) in Souza (2002), with average values oscillating between 6 and $8 \mathrm{mg} \mathrm{L}^{-1}$.

Oxygen biochemical demand values also indicated, according to Hamm (1969) in Souza (2002), condition varying from oligosaprobic $\left(0.3 \mathrm{mg} \mathrm{L}^{-1}\right)$ to $\alpha$-mesosaprobic $\left(8 \mathrm{mg} \mathrm{L}^{-1}\right)$, despite of the majority of its measurements be close to $5 \mathrm{mg} \mathrm{L}^{-1}$, i.e. conditions moderately polluted by organic matter ( $\alpha$-mesosaprobic).

Lepocinclis species richness at the Bom Jardim Creek varied from to nine taxa, the greatest number
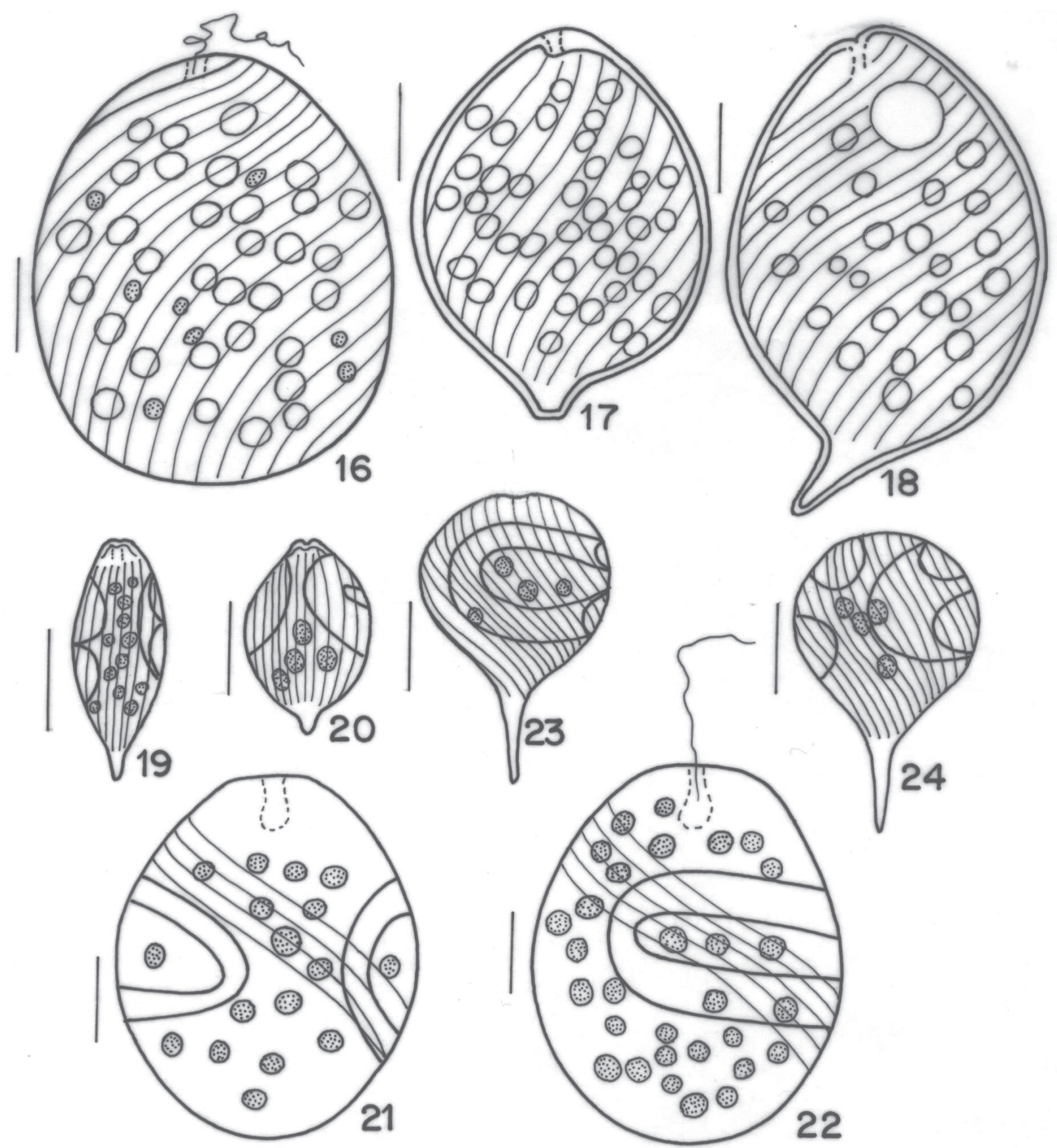
registered from ABJ Frente to Sitel, in November 2003 and May 2005.

Species richness varied seasonally among Bom Jardim Creek three sites presently studied, the summer being significantly different from all other seasons, possibly as a result of the greater water temperatures and organic matter availability, emphasis being given to orthophosphate and electric conductivity, which are the best eutrophication indicating organisms (Whitton 1975, Esteves 1998, Soininen et al. 2004).

\section{Acknowledgements}

To FAPERGS, Fundação de Amparo à Pesquisa do Estado do Rio Grande do Sul for Bolsa de Iniciação Científica to Karina Federle Consoni and Camila de Leon Louzada Borges (Proc. n. 08511100), to Lusiane Soares da Silva (Proc. n. 07511127). To Copesul, presently Braskem, for logistic help during samplings. To colleagues of Cryptogamic Botany Section of the Museu de Ciências Naturais, Fundação Zoobotânica do Rio Grande do Sul, for precious help during samplings, to Manoel Luis Nunes for chemical analyses and to Rejane Rosa for inking in the original drawings and to Arlete Ieda Pasqueletto for preparation of the map.

\section{Literature cited}

Alves-da-Silva, S.M. 1988. Euglenaceae pigmentadas (Euglenophyta) da Estação Ecológica do Taim, Rio Grande do Sul, Brasil. Iheringia, série Botânica 38: 109-126.

Alves-da-Silva, S.M. \& Ávila, I.R. 1997. Levantamento florístico das Euglenaceae pirgmentadas do Parque Estadual Delta do Jacuí, Rio Grande do Sul, Brasil. Iheringia, série Botânica 26: 85-102.

Alves-da-Silva, S.M. \& Bicudo, C.E.M. 2002. Contribution to the knowledge of genus Lepocinclis (Euglenophyceae) of the state of Rio Grande do Sul, Southern Brazil. Algological Studies 106: 77-97.

Alves-da-Silva, S.M. \& Bicudo, C.E.M. 2003. Strombomonas carinata sp. nov. and Strombomonas ferrazi sp. nov., two new Euglenophyceae from the state of Rio Grande do Sul, southern Brazil. Acta Botanica Brasilica 17: 147-154.

Alves-da-Silva, S.M. \& Bicudo, C.E.M. 2006. Contribution to the knowledge of genus Strombomonas (Euglenophyceae) of the state of Rio Grande do Sul, southern Brazil. Algological Studies 119: 29-58.

Alves-da-Silva, S.M. \& Crossetti, L.O. 1999. Novas citações de ocorrência de Euglenaceae pigmentadas para o estado do Rio Grande do Sul, Brasil. Hoehnea 26: 47-60.
Alves-da-Silva, S.M. \& Ferraz, G.C. 1991. Euglenaceae pigmentadas de cinco açudes da região carbonífera do município de São Jerônimo, Rio Grande do Sul, Brasil. Hoehnea 18: 143-135.

Alves-da-Silva, S.M., Ferraz, G.C. \& Torres, J.R. 1991. Euglenaceae pigmentadas de dois arroios e do rio Jacuí, região carbonífera do município de São Jerônimo, Rio Grande do Sul, Brasil. Revista Brasileira de Biologia 51: 813-828.

Alves-da-Silva, S.M. \& Fortuna, J.R. 2006. Euglenophyceae de ambientes lênticos na planície costeira do Rio Grande do Sul, Sul do Brasil: gêneros Euglena Ehr. e Lepocinclis Perty. Acta Botanica Brasílica 20: 411-422.

Alves-da-Silva, S.M. \& Hahn, A.T. 2004. Study of Euglenophyta in the Jacuí Delta State Park, Rio Grande do Sul, Brazil. 1. Euglena Ehr., Lepocinclis Perty. Acta Botanica Brasilica 18: 123-140.

Alves-da-Silva, S.M., Juliano, V.B. \& Ferraz, G.C. 2008. Euglenophyceae pigmentadas em lagoa ácida rasa, Parque Estadual de Itapuã, sul do Brasil. Iheringia, série Botânica 63: 15-36.

Alves-da-Silva, S.M. \& Laitano, C.S. 1994. Euglenaceae pigmentadas do Banhado do Jacaré, em um Parque de Proteção Ambiental, Triunfo, Rio Grande do Sul, Brasil. Iheringia, série Botânica 45: 89-116.

Alves-da-Silva, S.M. \& Torgan, L.C. 1981. Nota sobre euglenofíceas (Euglenaceae) de um açude no Morro Santana, Porto Alegre, Rio Grande do Sul, Brasil. Iheringia, série Botânica 28: 95-106.

Alves-da-Silva, S.M. \& Torres, J.R. 1992. Estudo taxonômico do gênero Lepocinclis Perty (Família Euglenaceae), Parque Zoológico de Sapucaia do Sul e Jardim Botânico de Porto Alegre, Rio Grande do Sul, Brasil. Iheringia, série Botânica 42: 87-104.

Alves-da-Silva, S.M. \& Torres, J.R. 1994a. O gênero Euglena Ehr. de sistemas lênticos do PZ e JB, Rio Grande do Sul, BR. Revista Brasileira de Biologia 54: 345-363.

Alves-da-Silva, S.M. \& Torres, J.R. 1994b. Estudo Taxonômico do gênero Phacus Duj. (Euglenaceae) no Parque Zoológico, Sapucaia do Sul e no Jardim Botânico, Porto Alegre Rio Grande do Sul. Iheringia, série Botânica 44: 45-83.

Alves-da-Silva, S.M. \& Torres, J.R. 1994c. O genero Strombomonas no Parque Zoológico, Sapucaia do Sul e no Jardim Botanico, Porto Alegre, Rio Grande do Sul, Brasil. Iheringia, série Botânica 44: 15-32.

American Public Health Association. 1992. Standards methods for the examination of water and waste water. 18 ed. Washington.

Brosnan, S., Brown, P.J.P., Farmer, M.A. \& Triemer, R.E. 2005. Morphological separation of the euglenoid genera Trachelomonas and Strombomonas (Euglenophyta) based on lorica development and posterior strip reduction. Journal of Phycology 41: 590-605. 
Brosnan, S., Shin, W., Kjer, K.M. \& Triemer, R.E. 2003. Phylogeny of the photosynthetic euglenophytes inferred from the nuclear SSU and partial LSU rDNA. International Journal of Systematic and Evolutionary Microbiology 53: 1175-11862.

Busse, I. \& Preisfeld, A. 2002. Phylogenetic position of Rhynchopus sp. and Diplonema ambulator as indicated by analyses of euglenozoan small subunit ribosomal DNA. Gene 284: 83-91.

Busse, I. \& Preisfeld, A. 2003. Systematic of primary osmotrophic euglenids: a molecular approach to the phylogeny of Distigma and Astasia (Euglenozoa). Journal of Systematics and Evolutionary Microbiology 53:617-624.

Cecy, I.I.T. 1990. A restinga do Pontal do Sul, município de Paranaguá, PR, 1: levantamento ficológico (Euglenophyta) e físico-químico. Arquivos de Biologia e Tecnologia 33: 1-79.

Chu, S.P. 1935. On Lepocinclis of Nanking. Sinesia 6: 158-184.

Chu, S.P. 1936. On new and rare species of Leponcinclis. Sinesia 7: 266-292.

Conrad, W. 1934. Matériaux por une monographie do genre Lepocinclis Perty. Archiv für Protistenkunde 82: 14-249.

Conrad, W. 1935. Etude systématique du genre Lepocinclis Perty. Musée Royal Naturelle de Belgique 1: 1-85.

Conti, J.B. \& Furlan, S.A. 2003. Geoecologia: o clima, os solos e a biota. In: J.L. Ross (ed.). Geografia do Brasil. Editora da Universidade de São Paulo, São Paulo, pp. 67-207.

Drezepolski, R. 1925. Przyczynek do znaiomósci polskich Euglenin (Supplément à la connaissance des Eugléniens de la Pologne). Kosmos 50: 173-270.

Esson, H.J. \& Leander, B.S. 2006. A model for the morphogenesis of strip reduction patterns in phototrophic euglenids: Evidence for heterochrony in pellicle evolution. Evolution \& Development 8: 378-388.

Esteves, F.A. 1998. Fundamentos de Limnologia. 2 ed. Interciência, Rio de Janeiro.

Ferreira, A.C.S. \& Menezes, M. 2000. Flora planctônica de um reservatório eutrófico, lagoa Guandu, município de Nova Iguaçu, RJ. Hoehnea 27: 45-76.

Franceschini, I.M. 1992. Algues d'eau douce de Porto Alegre Brésil (les Diatomophycée exclues). Berlin. Biblioteca Phycologica 92: 1-81.

Hamm, A. 1969. Die Ermittlung der Gewässergüteklassen bei Flibgewässern nach dem Gewässergütsystem und Gewässergütenomogramm. Münchner Beiträge zur Abwasser Fischerei und Flußbiologie, 15: 46-48.

Huber-Pestalozzi, G. 1955. Das Phytoplankton des Süßwassers: Systematik und Biologie: Euglenaceen. v. 16. E. Schweizerbart'sche Verlangsbuchhandlug, Stuttgart.
Huszar, V.L.M. 1979. Ocorrência e Distribuição Sazonal do Fitoplâncton do Lago da Barragem Santa Bárbara, Pelotas, Rio Grande do Sul, Brasil. Revista Brasileira de Botânica 2: 149-154.

Huszar, V.L.M., Menezes, M. \& Fernandes, V.O. 1989. Fitoplâncton de rede da lagoa Cabiúnas, Macaé, Estado do Rio de Janeiro, Brasil: uma contribuição a seu conhecimento. Boletim do Museu Nacional 78: 1-43.

Kosmala, S., Karnkowska, A., Millanowski, R., Kwiatowski, J. \& Zakrys, Z. 2005. Phylogenetic and taxonomic position of Lepocinclis fusca comb. nov. (= Euglena fusca) (Euglenaceae): morphological and molecular justification. Journal of Phycology 41: 1258-1267.

Leander, B.S. \& Farmer, M.A. 2000a. Comparative morphology of the euglenid pellicle. I. Patterns of strips and pores. Journal of Eukaryotic Microbiology 47: 469-79.

Leander, B.S. \& Farmer, M.A. 2000b. Epibiotic bacteria and a novel pattern of strip reduction on the pellicle of Euglena helicoideus (Bernard) Lemmermann. European Journal of Protistology 36: 405-413.

Leander, B.S. \& Farmer, M.A. 2001a. Comparative morphology of the euglenid pellicle, 2: diversity of strip substructure. Journal of Eukaryotic Microbiology 48: 202-217.

Leander, B.S. \& Farmer, M.A. 2001b. Evolution of Phacus (Euglenophyceae) as inferred from pellicle morphology and SSU rDNA. Journal of Phycology 37: 143-159.

Leander, B.S., Witek, R.P. \& Farmer, M.A. 2001. Trends in the evoluton of the euglenid pellicle. Evolution 55: 2115-2135.

Lemmermann, E. 1910. Kryptogamenflora der Mark Brandenburg, 3. Algen I. Schizophyceen, Flagellaten, Peridineen. Verlag von Gebrüder, Bornträger, Leipizig.

Linton, E.W., Hittner, D., Lewandowski, C., Auld, T. \& Triemer, R.E. 1999. A molecular study of euglenoid phylogeny using small subunit rDNA. Journal of Eukaryotic Microbiology 46: 217-223.

Linton, E.W., Nudelman, M.A., Conforti, V. \& Triemer, R.E. 2000. A molecular analysis of the euglenophytes using SSU rDNA. Journal of Phycology 36: 740-746.

Lobo, E.A. \& Buselato-Toniolli, T.C. 1985. Tempo de exposição de um substrato artificial para o estabelecimento da comunidade do perifíton no curso inferior do Rio Caí, Rio Grande do Sul, Brasil. Rickia 12: 36-51.

Marin, B., Palm, A.O., Klingberg, M. \& Melkonian, M. 2003. Phylogeny and taxonomic revision of plastidcontaining Euglenophytes based on SSU rDNA Sequence comparisons and synapomorphic signatures in the SSU rRNA Secondary Struture. Protist 154: 99-145. 
Menezes, M. 1990. Estudos taxonômicos sobre o gênero Lepocinclis Perty (Euglenaceae) no Município do Rio de Janeiro e arredores, Brasil. Revista Brasileira de Biologia 50: 103-113.

Németh, J. 1980. Az ostoros Algák (Euglenophyta). série Hidrobiológia 8. Kishatározóija Vizdock, Budapeste.

Preisfeld, A., Berger, S., Busse, I., Liller, S. \& Ruppel, H.G. 2000. Phylogenetic analyses of various euglenoid taxa (Euglenozoa) based on $18 \mathrm{~S}$ rDNA sequence data. Journal of Phycology 36: 220-226.

Preisfeld, A., Busse, I., Klingberg, M., Talke, S. \& Ruppel, H.G. 2001. Phylogenetic position and interrelationships of the osmotrophic euglenoids based on SSU rDNA data, with emphasis on the Rhabdomonadales (Euglenozoa). International Journal of Systematics and Evolutionary Microbiology 51: 751-758.

Pringheim, E.G. 1953. Observations on some species of Trachemononas grown in culture. New Phytologist 53: 93-113.

Rosa, Z.M., Aguiar, L.W. \& Corte-Real, M. 1974. Nota sobre gêneros de algas continentais do município de Porto Alegre, Rio Grande do Sul, Brasil, Iheringia, série Botânica 19: 53-62.

Rosa, Z.M., Torgan, L.C. \& Lobo, E.A. 1988. Análise da estrutura de comunidades fitoplanctônicas e de alguns fatores abióticos em trecho do Rio Jacuí, no Rio Grande do Sul, Brasil Acta Botanica Brasilica 2: 31-46.

Rosa, Z.M., Ungareti, I. \& Kremer, L.M. 1987. Ficoflora de ambientes lênticos - estudo preliminar da região de Charqueadas, Rio Grande do Sul, Brasil, com vistas à avaliação ambiental. Acta Botanica Brasilica 1: 165-188.

Round, F.E. 1983. Biologia das algas. 2 ed. Editora Guanabara Dois, Rio de Janeiro.
Shi, Z., Wang, Q., Xie, S. \& Dai, J. 1999. Euglenophyta. Flora Algarum Sinicarum Aquae Dulcis 6. Science Press, Beijing.

Soininen, J., Paavola, R. \& Muotka, T. 2004. Benthic diatom communities in boreal streams: community structure in relation to environmental and spatial gradients. Ecography 27: 330-342.

Sommer, C.H. 1977. Produção primária do fitoplâncton da Represa Lomba do Sabão (Viamão, RS). Dissertação de Mestrado, Universidade Federal do Rio Grande do Sul, Porto Alegre.

Starmach, K. 1983. Euglenophyta. In: K. Starmach (ed.) Flora Slodkowodna Polski, 3. Polska Academia Nauk, Warszawa.

Tell, G. \& Conforti, V.T.D. 1986. Euglenophyta pigmentadas de la Argentina. J. Cramer, Berlin.

Torgan, L.C., Menegheti, J.O. \& Silva, S.M.A. 1979. Contribuição ao estudo do fitoplâncton do rio Caí, Rio Grande do Sul, Brasil. In: Anais do $30^{\circ}$ Congresso Nacional de Botânica, Campo Grande, pp. 142-146.

Wetzel, R.G. 2001. Limnology: lake and river ecosystems. Elsevier Science, Orlando.

Whitton, B.A. 1975. River ecology. Blackwell Scientific Publications, London.

Wolowski, K. 1998. Taxonomic and environmental studies on euglenophytes of the Kraków-Czestochowa Upland (Southern Poland). Fragmenta Floristica et Geobotanica, Suppl. 6: 3-192.

Xavier, M.B. 1989. O gênero Lepocinclis Perty de lagos do Parque Estadual das Fontes do Ipiranga, São Paulo, Brasil. Hoehnea 16: 133-147.

Xavier, M.B. 1994. Criptógamos do Parque Estadual das fontes do Ipiranga, São Paulo, SP. Algas, 5: Euglenophyceae (Euglenaceae pigmentadas). Hoehnea 2: 47-73. 